\title{
Comparative Analysis of the Energy Dissipation of Steel Buildings with Concentric and Eccentric Braces
}

\author{
Edelis del V. Marquez A., ${ }^{1,}$, William Lobo-Q ${ }^{1}$ and Juan C. Vielma ${ }^{2, *}$ \\ ${ }^{1}$ Universidad de los Andes, Mérida, Venezuela \\ ${ }^{2}$ Universidad Centroccidental Lisandro Alvarado, Barquisimeto, Venezuela
}

\begin{abstract}
A comparative study has been done to analyze the behavior of regular steel building structures of 4, 6, 8 and 10 stories, located in seismic zone 5 and soil type S1. The structures were upgraded with different brace configurations according to current Venezuelan codes. A total number of 24 numerical models were analyzed considering non-linear static and incremental dynamic analysis (IDA). The buildings were initially designed as moment resisting frames, and upgraded with six different bracing configurations: concentric braces in "X" and inverted "V"; eccentric braces inverted "V" with horizontal links, inverted "Y" and "X" with vertical links. Short length links were used to ensure a shear failure.

The used methodology is based on obtaining the capacity, IDA curves, and bilinear approximations of these curves that allow the determination of yield and ultimate capacity points, in order to estimate important parameters of seismic response: overstrength and ductility; and considering these areas under the curves to estimate elastic deformation energy, energy dissipated by hysteretic damping and equivalent damping.

According to the results, the cases with no brace enhancement showed the lowest lateral strength and lateral stiffness and high deformation capacity. On the other hand, the concentric bracing cases, resulted with the highest stiffness and strength and the lowest deformation capacity, therefore they have low ductility and energy dissipation capacity under seismic loading. Structures with links showed intermediate stiffness and strengths, resulting in the best performance in terms of ductility and energy dissipation capacity. The present study provides a better understanding of the benefits of eccentrically braced systems.
\end{abstract}

Keywords: Concentric braces, dissipated energy, eccentric braces, incremental dynamic analysis, non-linear analysis, upgraded.

\section{INTRODUCTION}

In developing countries, it is necessary to design economical steel building to obtain additional energy dissipation capacity under seismic actions, avoiding expensive solutions such as base isolation or energy dissipating devices. Therefore, it is desirable to propose practical solutions for new structures and existing conventional moments resisting frames (MRF) structures located in zones of high seismic hazard with inadequate security under earthquake [1]. The eccentrically braced frames (EBF) could be a suitable solution to obtain the required strength, stiffness and energy dissipation capacity on steel buildings [2,3].

The behavior of structures under seismic actions depends on many factors such as the system used to resist lateral forces, construction materials and structural configurations. These factors usually have important implications in the final deformation, energy dissipation and resistant capacity. For a satisfactory seismic performance, the system must have

*Address Correspondence to these Authors at the Universidad de los Andes, Mérida, Venezuela; Tel: 58+2742402869; Fax: 58+2742402862;

E-mail: edelismarquez@gmail.com and Universidad Centroccidental Lisandro Alvarado, Barquisimeto, Venezuela; Tel: 58+2512592135;

Fax: 58+2512592104; E-mail: jcvielma@cimne.upc.edu suitable structural rigidity and strength, high ductility, stability and redundancy [4]. Some lateral force resisting systems have only few of these properties; in these cases, different systems or structural components can be combined to improve the overall seismic response. Dual systems could combine frames and brace components being more effective than those components used separately.

Many variants exist for frames with braces, which are an efficient way to resist seismic forces. A suitable distribution of stiffening elements can maintain the advantages of moments resisting frames (MRF), improving the global behavior with higher rigidity and resistance to lateral loads $[5,6]$. However, some aspects must be taken into account to avoid inadequate seismic behavior $[7,8]$. Research has shown that the eccentric bracing frames (EBF) have the ability to combine a high stiffness in the elastic range, and also excellent ductility and energy dissipation in the inelastic range. In the elastic range, the lateral rigidity is comparable with the concentrically diagonal frame (CBF) particularly when the link is short. In the inelastic range, EBF exhibits a stable ductile behavior under severe load cycles, comparable to the MRF [9].

The Venezuelan seismic code COVENIN 1756-2001 [10] classifies the structures according to their use, design 


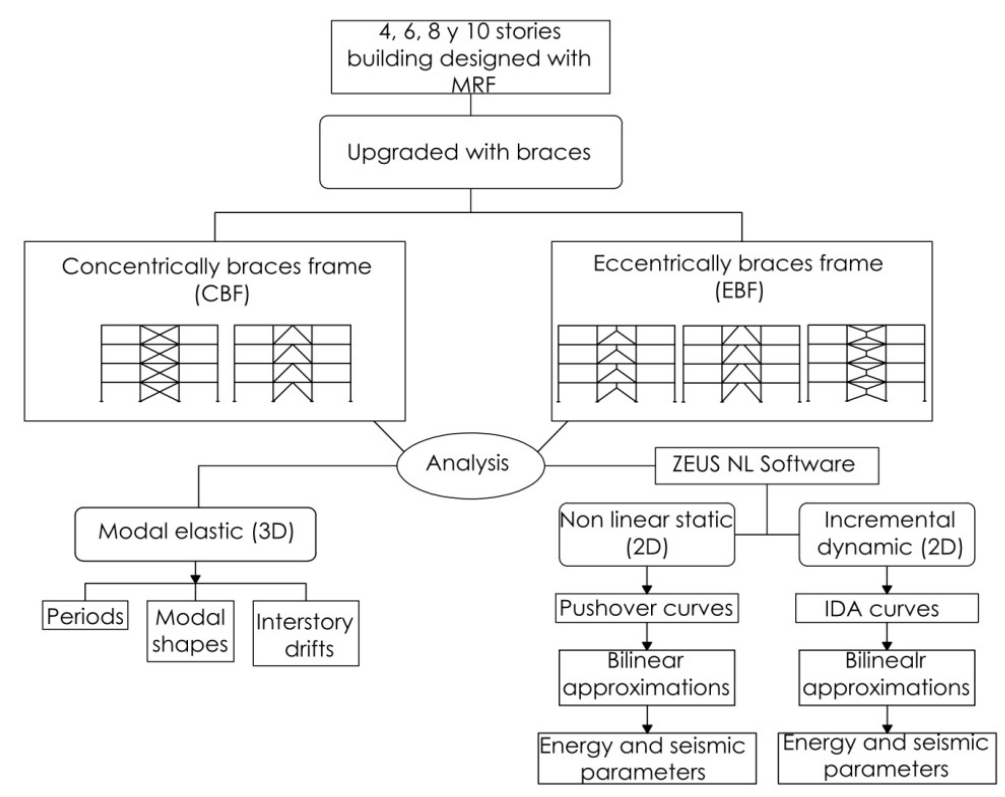

Fig. (1). Research methodology.

class, typology and structural regularity. Four types of seismic resistant systems are identified, depending on the structural elements that are required to resist seismic action and gravity loads. CBF and EBF belong to type III classification; The MRF to type I; and type II corresponds to the combination of types III and I.

In CBF, columns, beams and braces (zones of energy dissipation) intersect at a point and they are expected to yield under moderate to high earthquakes; while EBF is composed by columns, beams and braces in which at least one end of the bracing is connected to the beam at a distance from the connecting beam-column. The distance between the beam and bracing connection or distance between connections and the braces is called "link", zone of energy dissipation.

\section{METHODOLOGY}

The methodology is based on the design of a set of $4,6,8$ and 10 stories steel buildings, using conventional moment resistant frames. Subsequently, these buildings were upgraded by incorporating different configurations of concentric and eccentric braces (Fig. 4). Then modal elastic analysis, non-linear static analysis and incremental dynamic analysis are performed in order to obtain the capacity curves and IDA curves. Bilinear approximations of these curves allow the determination of yield and last capacity points, therefore the ductility, overstrength, and energy dissipation. Fig. (1) shows the research methodology described above. Non-linear analyses were made by the software ZEUS NL, considered as a system for inelastic analysis of structures; a way to solve non-linear dynamic time-history, conventional and adaptive pushover and eigenvalue analysis.

\subsection{Non-Linear Analysis}

The non-linear responses have been carried out using incremental static analysis (pushover analysis) and incremental dynamic analysis (IDA) using synthetic accelerograms [1113], created under design spectrum of COVENIN 1756 2001 to type 1 soil.

\subsubsection{Incremental Static Analysis or Pushover Analysis}

Non-linear static procedure has found its widespread use in the performance-based seismic design, since they offer a relatively simple approach for estimating inelastic structural responses [14]. Currently, the force-based design dominates the state of the practice; however, the performance-based design engineering has received attention in the past decade, increasing the number of non-linear methods. Pushover analysis is a widely and popular approach used to establish the non-linear behavior, in which a mathematical model of the structure is subjected to constant gravity load and to a monotonical increase of lateral force or displacement [15, 16]. Generally, the lateral load pattern is triangular; however, this arrangement can lead to incorrect or inadequate estimates representations of the effects of dynamic variation for the inelastic response when the structure has significant influence of higher modes. In this study, a modal combination method (MMC) that implicitly represents effects of higher modes is based on invariant force distribution resulting from the independent modes contributions that have been used [17].

\subsubsection{Incremental Dynamic Analyses (IDA)}

Incremental dynamic analysis (IDA) is a method that can be used to estimate structural capacity under earthquake loading. It provides a continuous history of the system response, from elasticity to yielding behavior and finally to collapse. The rationale behind the IDA is derived by analogy with the incremental static analysis, or pushover.

The IDA method analyzes the structural model for one or more ground - motion records, each of them scaled to multiple intensity levels. For every scaling factor, the maximum 


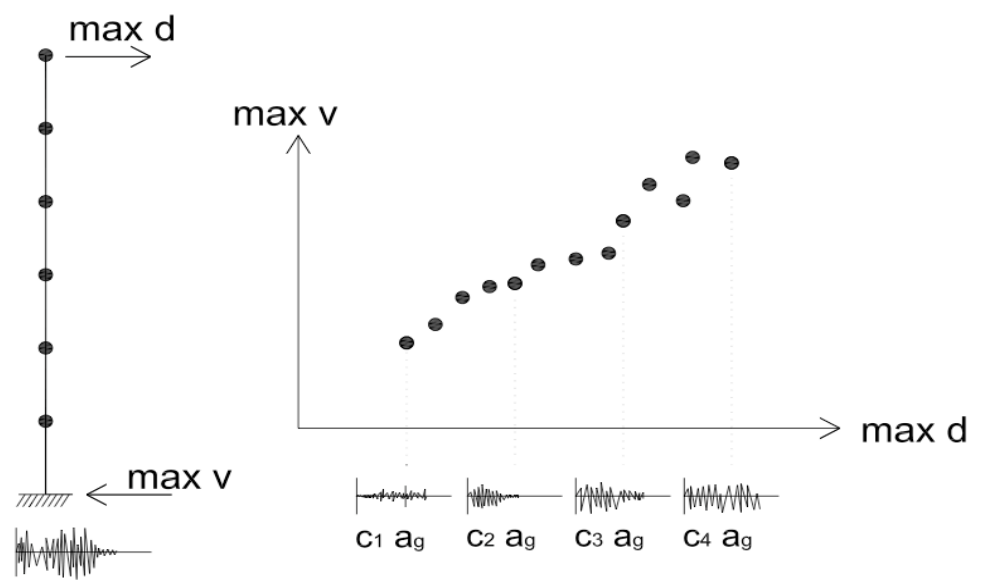

Fig. (2). Incremental dynamic analysis (IDA) approach.

response parameters (shear-drift, moment-curvature etc.) are plotted on a 2D graph, just like static pushover curves. The difference is that every single point represents a full run inelastic dynamic analysis, whereas in the static pushover curve a single point represents a load step. The incremental dynamic analysis has the advantage of being accurate for seismic analysis, however, it is computationally expensive. Fig. (2) shows the incremental dynamic analysis (IDA) approach.

\subsection{Seismic Response and Energy Dissipation Parame- ters}

There are important seismic response parameters, among them we can mention: ductility, overstrength, interstorey drifts and damping.

Ductility is defined as the ability of a material, component, connection or structure to undergo inelastic deformations, with acceptable stiffness and strength reduction. The response amplitudes of earthquake induced vibrations are dependent on the level of energy dissipation of structures, which is a function of their ability to absorb and dissipate energy by ductile deformations [18].

The definition of displacement ductility is given below:

$$
\mu=\frac{\Delta}{\Delta y}
$$

where $\Delta \mathrm{u}$ and $\Delta \mathrm{y}$ are displacements at ultimate and yield points respectively.

Overstrength factor, reflects the reserve strength and the anticipated behavior of the structure under the design earthquake, is defined as follows:

$$
\Omega=\frac{\mathrm{V}_{\mathrm{u}}}{\mathrm{V}_{\text {ep }}}
$$

where Vep is the elastic strength and $\mathrm{Vu}$ is ultimate lateral strengths of the system.

To evaluate the seismic response and damage to structures the interstorey drift is often used, which represents the angular distortion for the columns of a given level and is calculated as:
$\delta_{i}=\frac{\left(\Delta_{i}-\Delta_{i-1}\right)}{\left(H_{i}-H_{i-1}\right)}$

where $\delta \mathrm{i}$ and $\delta \mathrm{i}-1$ are the inelastic displacements of levels i e $\mathrm{i}-1$, respectively calculated according with COVENIN 17562001, by the following expression: $\delta \mathrm{i}=0.8 \mathrm{R} \delta \mathrm{ei}$, where $\mathrm{R}=6$ is the response factor and $\delta$ ei is the elastic lateral displacement of level (i). Hi and Hi-1 are the heights at these levels, measured with respect to the lower level of the building.

Damping is utilized to characterize the ability of structures to dissipate energy during dynamic response. Structural components in the energy imparted by earthquakes is primarily dissipated through hysteretic damping, characterized by the loop of action-deformation, these cycles represent the action-strain relationship of materials, sections, members, connections or reversible systems under load.

The energy dissipated by the hysteresis loops can be represented as equivalent viscous damping ( $(\mathrm{eq})$ associated with a maximum displacement and can be estimated by Equation (4). This damping action occurs when a seismic structure leads to the inelastic range, and may be as a combination of the inherent viscous damping and hysteretic damping $[19,20]$.

$\xi_{e q}=\xi_{0}+\xi_{\text {hist }}$

where $\xi_{0}$ is the inherent structure viscous damping in the elastic range, this can vary in practice between $2 \%$ and $5 \%$. Furthermore the response corresponding to the hysteretic damping hysteretic $\xi$ hist (equivalent viscous) may be calculated from Equation (5):

$\xi_{\text {hist }}=\frac{E_{D}}{4 \pi E_{S O}}$

where:

$$
\begin{aligned}
& E_{D}=4\left(S_{a y} S_{d p i}-S_{a p i} S_{d y}\right) \\
& E_{S O}=\frac{S_{d p i} S_{a p i}}{2}
\end{aligned}
$$


- $\mathrm{E}_{\mathrm{D}}=$ energy dissipated by hysteretic damping.

- $E_{s o}=$ Maximum strain energy absorbed by the structure.

$\mathrm{E}_{\mathrm{D}}$ and $E_{s o}$, can be calculated from the bilinear approximation of the capacity and IDA curves, where $S_{d p i}$ and $S_{\text {api }}$ correspond to last capacity point in the "X" and "Y" axes respectively, while $S_{d y}$ and $S_{a y}$ correspond to yield point values.

\section{DESCRIPTION OF CASES IN STUDY}

To study the seismic response and energy dissipation of buildings with braces, regular steel structures of 4, 6, 8 and 10 stories, with 3 spans of $6 \mathrm{~m}$ in $\mathrm{X}$ and $\mathrm{Y}$ directions, and 3 $\mathrm{m}$ the height of interstorey have been selected. The buildings were initially designed as moment resisting frames, and subsequently upgraded by incorporating six different concentrically and eccentrically bracing configurations, located in the central spans of each perimeter frames, in order to obtain a noninvasive condition within buildings. A total number of 24 numerical models were analyzed.

The use of the building in study is office (B2 group, according COVENIN 1756-2001). The structural profiles used in the design correspond to European profiles HEB in columns and bracings, and IPE in beams, which are common in the Venezuela engineering practice and also they meet the requirements specified in COVENIN1618-1998. The interstorey is a flat slab armed in two directions, considered in the analysis as a rigid diaphragm. The orientation of the columns has been arranged so as to achieve symmetry in both directions. Fig. (3) shows the typical floor plan of the buildings, common for each case studied, where the column orientation and location of bracing on the perimeter frames are indicated.

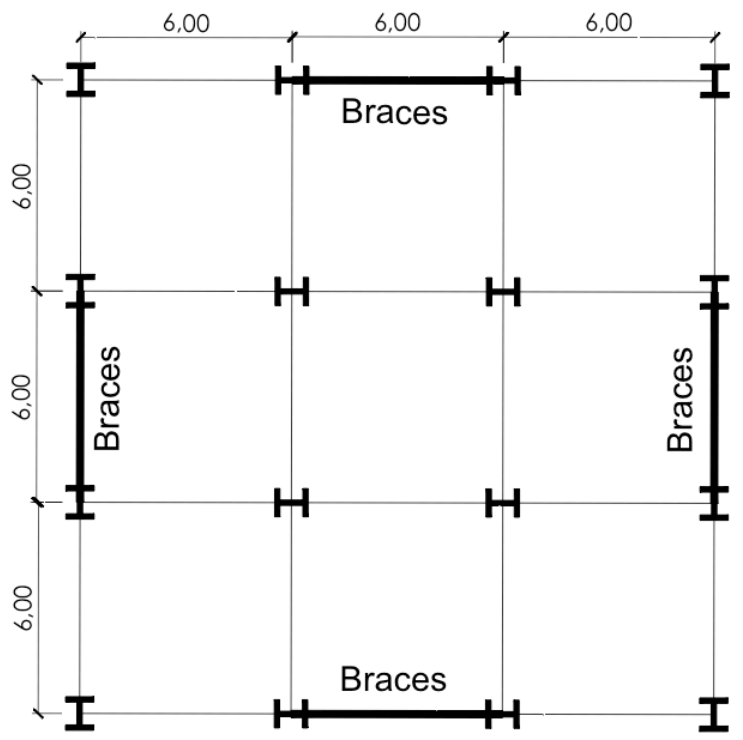

Fig. (3). Typical floor plan of the buildings.
For the upgrading two (2) concentric diagonal configurations have been chosen: $\mathrm{CBF}$ in $\mathrm{X}$ (configuration 2) and $\mathrm{CBF}$ in inverted $\mathrm{V}$ (configuration 3), commonly known as $\mathrm{X}$ braced system and Chevron type respectively; and three (3) eccentric brace configurations: EBF in inverted "V" with horizontal link (configuration 4), EBF in inverted "Y"(configuration 5) and EBF in "X" with vertical link (configuration 6). In Fig. (4), three-dimensional models of the six (6) configurations in the study are shown for 4 stories buildings; the same configurations apply to 6,8 and 10 stories buildings.

The buildings were designed according the requirements Venezuelan code COVENIN 1618-1998, applying gravity loads and seismic demand according to the elastic design spectrum fortype $\mathrm{S} 1$ soil and 0,3gacceleration, corresponding to a region of high seismic hazard. The design and detailed required by COVENIN codes, results in structures capable of dissipate energy, and reaching a high ductility; therefore ND3 design classis adopted, because this requires the application of all additional requirement for design in seismic zones established in COVENIN code which is the most demanding in terms of connection detailing, but that also allows to consider a reduction factor $(\mathrm{R})$ to obtain the inelastic spectrum design, necessary to define the seismic actions on the structure. Fig. (5) shows the representation of elastic and inelastic design spectrum considered $\mathrm{R}=6$ (according the type of steel structure, design class and soil used in this study).

The seismic action defined on designed buildings, provides combining orthogonal effects, applying $100 \%$ in one direction and $30 \%$ in the other two directions. This combination of effects is particularly important in structures with compression and traction braces.

\section{DISCUSSION OF RESULTS}

Results of the cases studied are presented in this section. First of all it is shown the corresponding interstorey drifts computed from modal elastic analysis $3 \mathrm{D}$, then the curves from non-linear static and incremental dynamic analysis of 2D mathematical models are shown. Finally seismic response and dissipation energy parameters are also shown.

\subsection{Modal Elastic Analysis}

According to COVENIN 1756-2001, 1,8\% is the maximum interstorey drift allowed corresponding to B2 structures group (considered in this study) and susceptible to experiment damages of non-structural elements. Notable differences are observed between interstorey drifts obtained from the six configurations in study. Modal analysis showed (Fig. 6) a similar behavior of each configuration to vary the height of the buildings.

The maximum interstorey drifts values correspond to configuration 1(MRF, without braces buildings) and the minor values it refer to configuration 2 and 3 (CBF in " $\mathrm{X}$ " and inverted "V"), the most rigid conditions. The other configurations make medium condition, but reducing the displacement by the braces, in degradation of effectiveness these are EBF in inverted "V" with horizontal link (Configuration 4), $\mathrm{EBF}$ in inverted " $\mathrm{Y}$ " (Configuration 5) and EBF in " $\mathrm{X}$ " with 


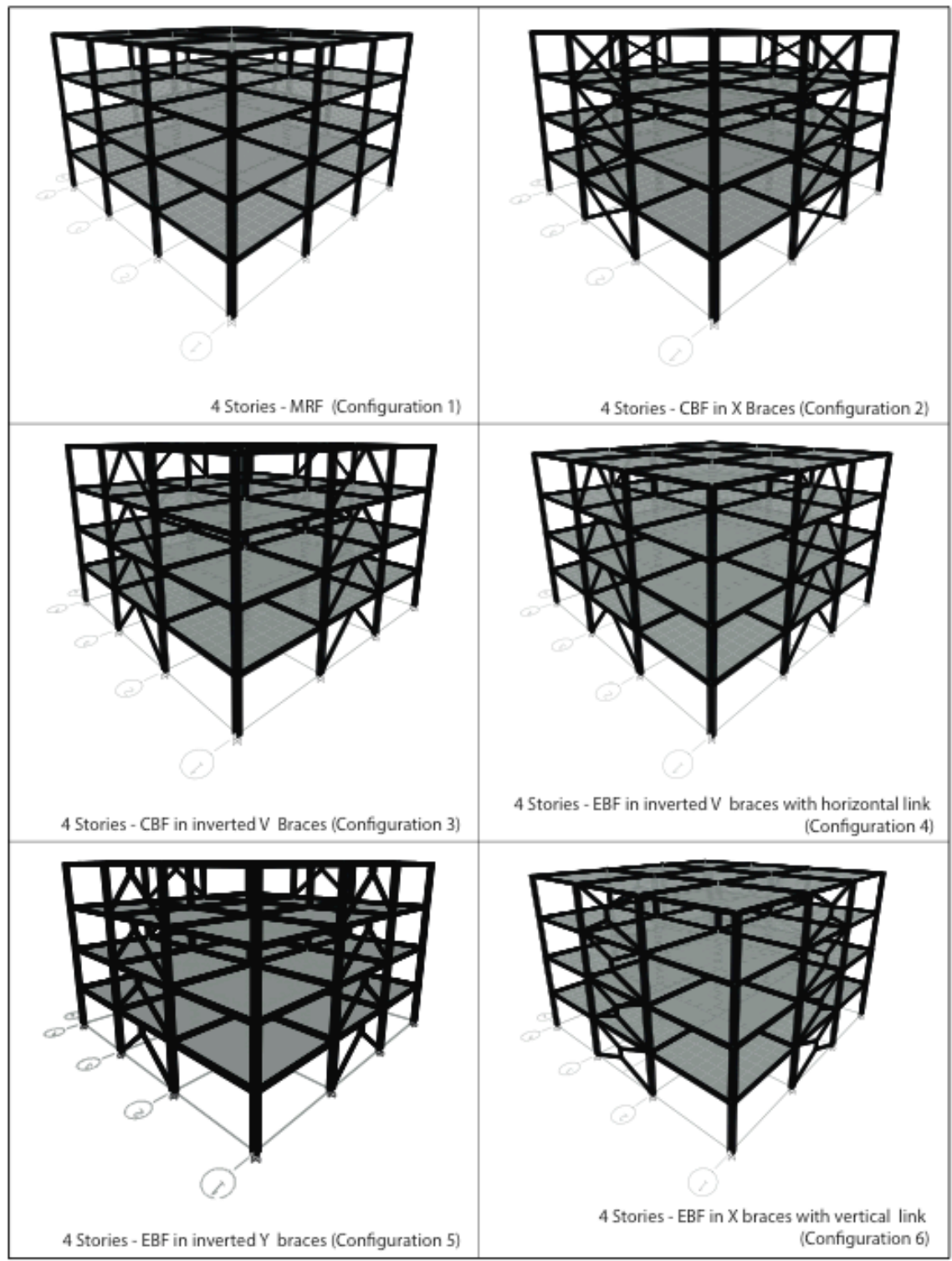

Fig. (4). 3D model of the six configurations studied (4 stories buildings).

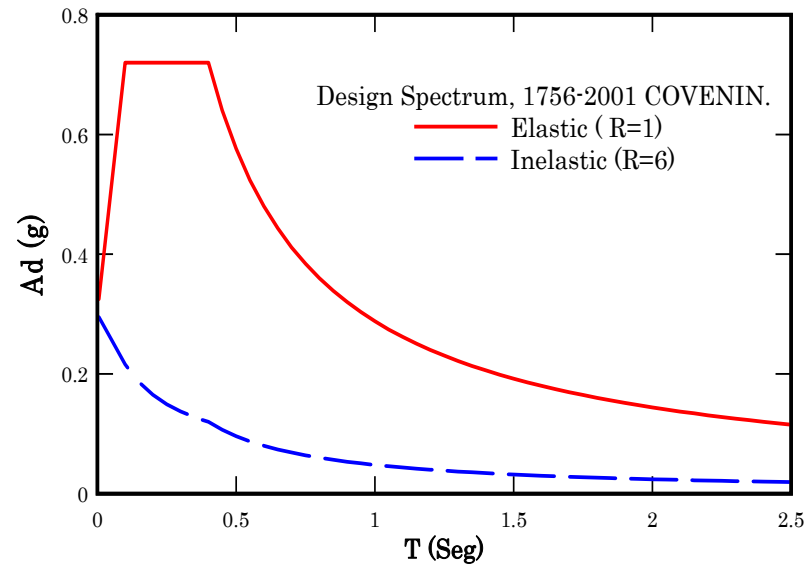

Fig. (5). Design Spectrum 1756-2001 COVENIN, S1 soil type.

vertical link (Configuration 6). These results will be calibrated by non-linear analysis.

\subsection{Non-Linear Incremental Static Analysis}

The capacity curves (pushover) with the bilinear approximation obtained from non-linear static analysis, in the 24 cases studied are presented in Figs. (7-10). The ultimate point considered in the bilinear approximation curve corresponds with the highest base shear of pushover curve. According to results for different levels of the studied buildings: (4, 6, 8 and 10 stories), the behaviors are similar for each configuration. The capacity curves of frames without braces (configuration 1) has the lowest strength and lateral stiffness and the highest displacement in the roof corresponding to maximum base shear; therefore, the highest deformation capacity. Concentrically braces in "X" (configuration 2) and inverted "V" (configuration 3) are the others extreme conditions with the highest initial strength and stiffness but the more lowest capacity of displacement in the roof and deformation capacity according to these maximum base shear. When eccentrically braces are present, the pushover curves given an intermediate response, The curves corre- 


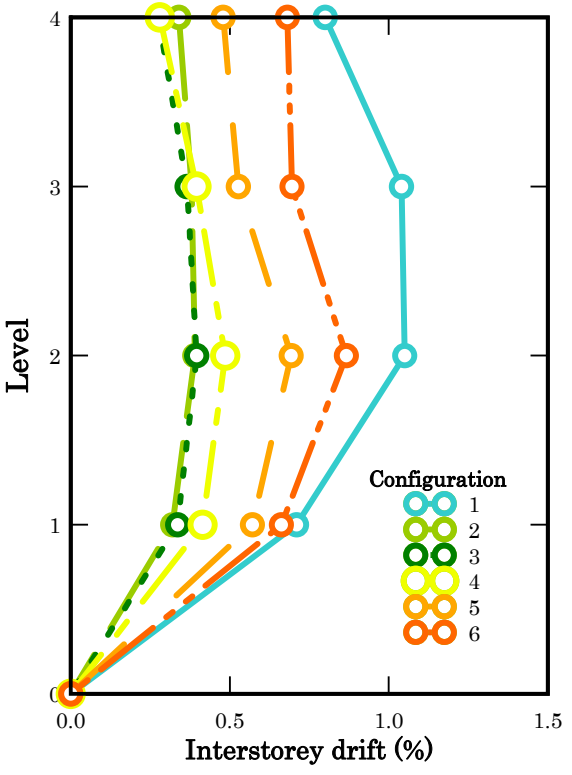

(a)

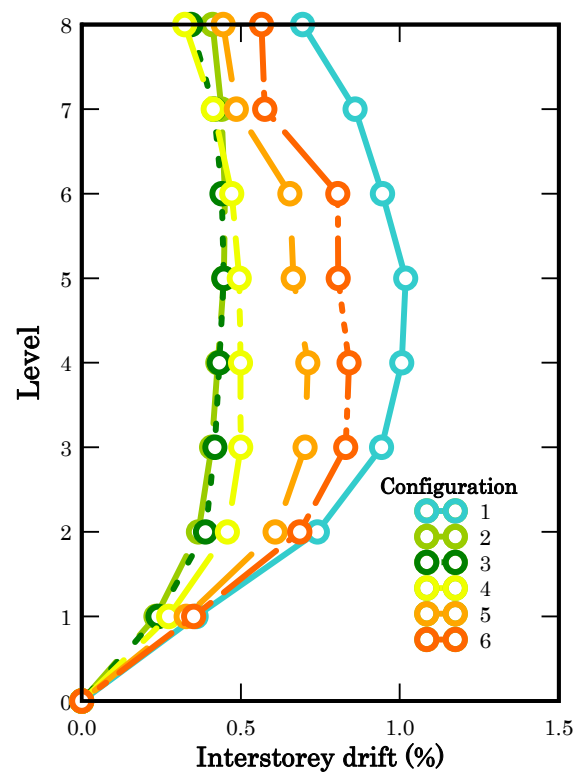

(c)

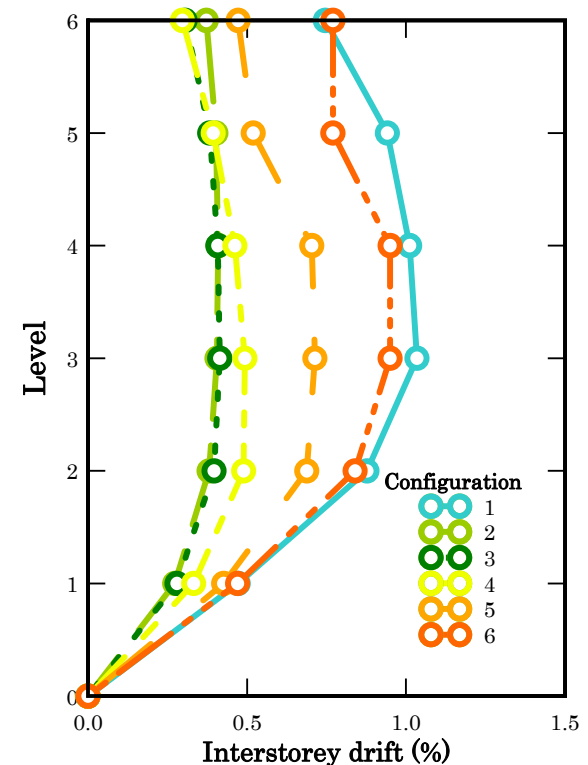

(b)

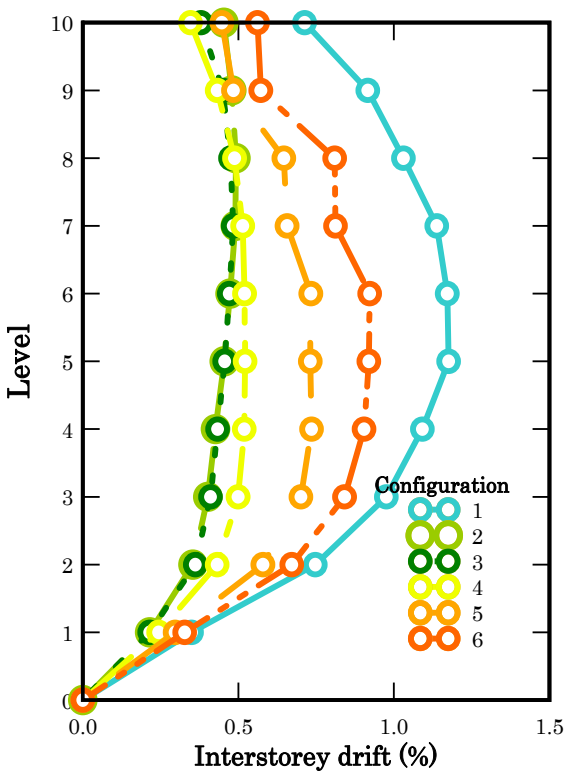

(d)

Fig. (6). Interstorey drifts from the cases studied, 4 (a), 6 (b), 8 (c) and 10 (d) stories buildings.

sponding to EBF in inverted "Y" and "X" with vertical link (configurations 5 and 6) have a behavior similar. Between EBF configurations, inverted "V" with horizontal links on the beam (configuration 4 ) obtained the highest base shear. It is possible to improve the EBF condition by the buckling restrained brace (BRB), which are a better technology, this solution has been shown in other papers [21].

\subsection{Incremental Dynamic Analysis}

The results of incremental dynamic analysis (IDA curves) shown the average curves from the used of three synthetic accelerograms (minimum number of suggested accelerograms in several researches) obtained according to design spectrum COVENIN1756-2001. Additionally it is shown the bilinear approximation in each curve (Figs. 11-
14). Is important to note that ultimate point (considering before the collapse of the buildings) is reached when the stiffness of the IDA curve is less than or equal to $20 \%$ of the initial stiffness (elastic slope) [21].

According to the results, each specific configuration follows a similar pattern of behavior for the different heights of buildings considered, just as the non-linear static analysis result. The MRF (configuration 1) has the lowest resistance, while the $\mathrm{CBF}$ cases have the highest rigidity and resistance. EBF is located in an intermediate position between CBF and MRF. The maximum roof level displacement corresponding to maximum base shear obtained shows that the greatest displacement are obtained from MRF (configuration 1), followed by configurations 6,5 and 4 of EBF. 


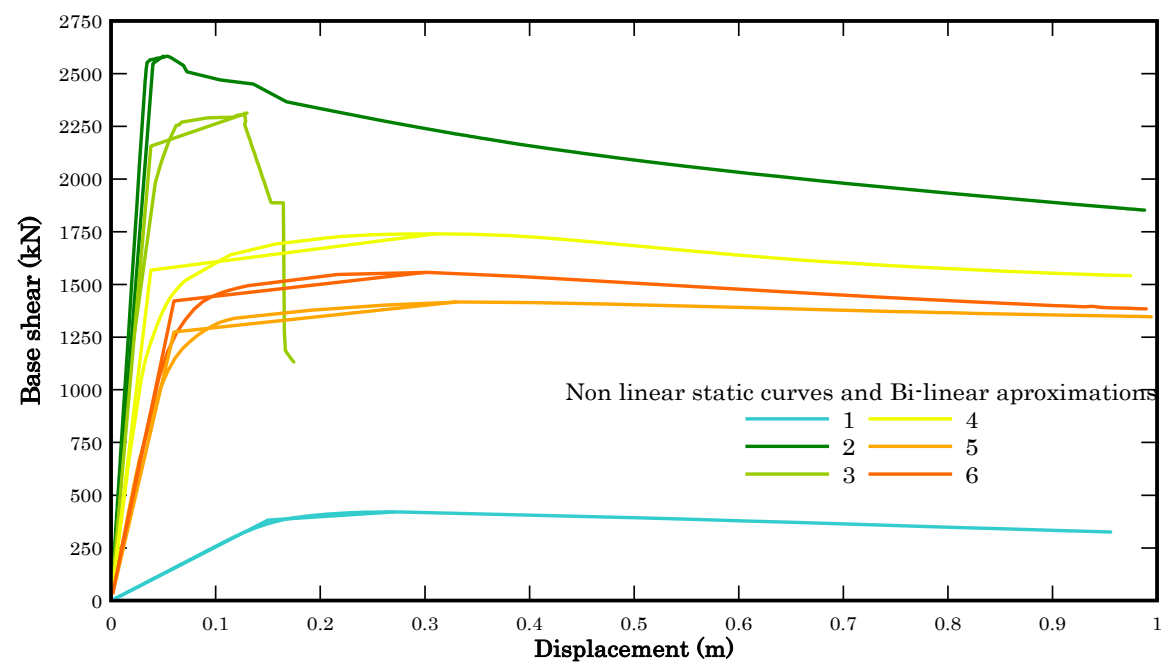

Fig. (7). Capacity curves and bilinear approximations for 4 stories buildings.

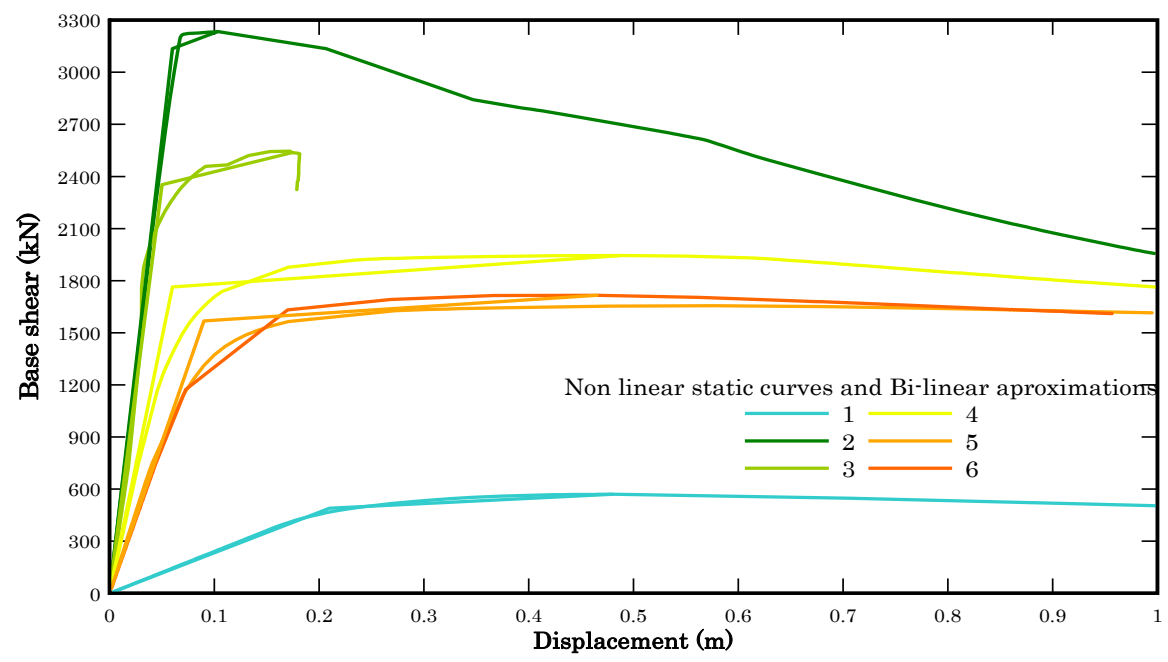

Fig. (8). Capacity curves and bilinear approximations for 6 stories buildings.

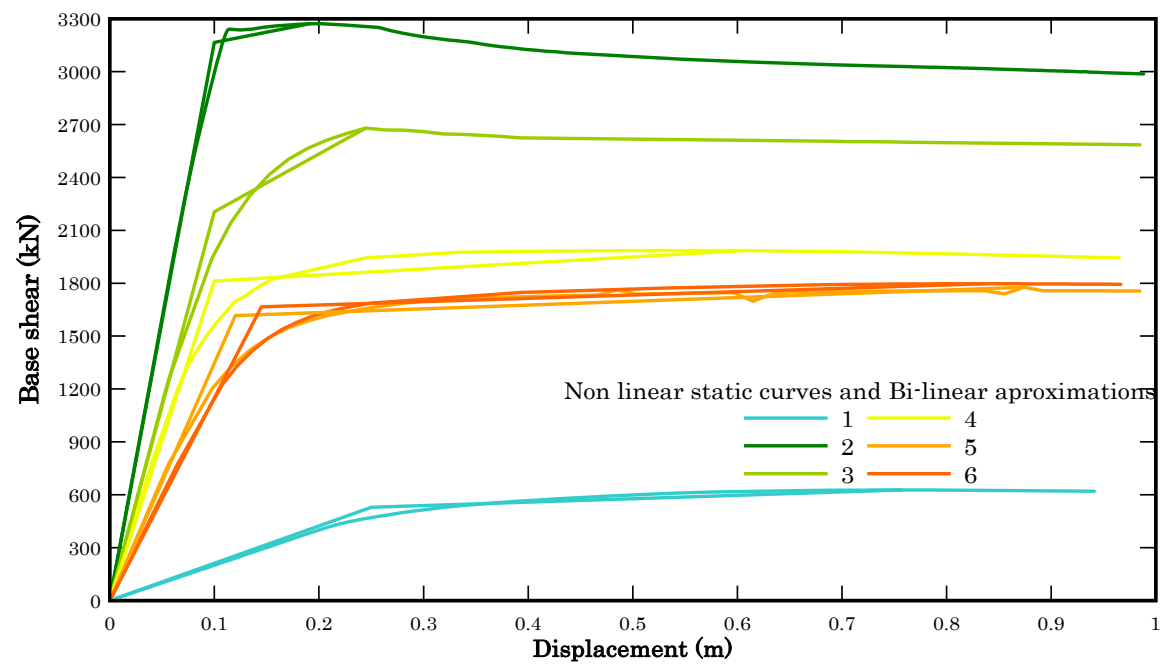

Fig. (9). Capacity curves and bilinear approximations for 8 stories buildings. 


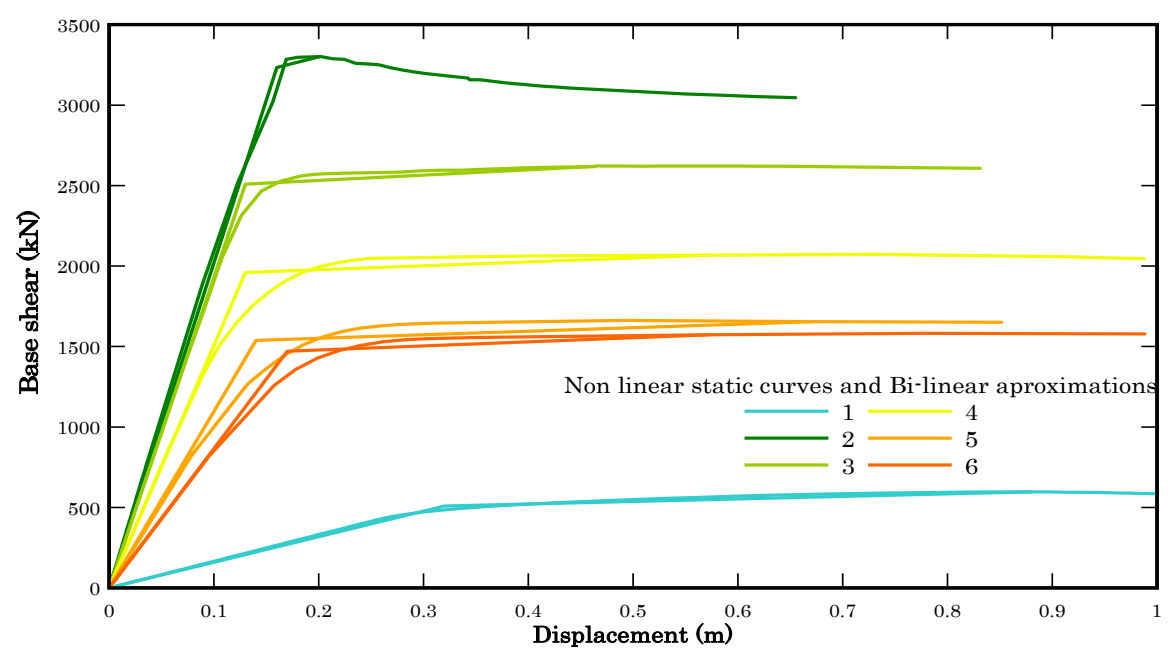

Fig. (10). Capacity curves and bilinear approximations for 10 stories buildings.

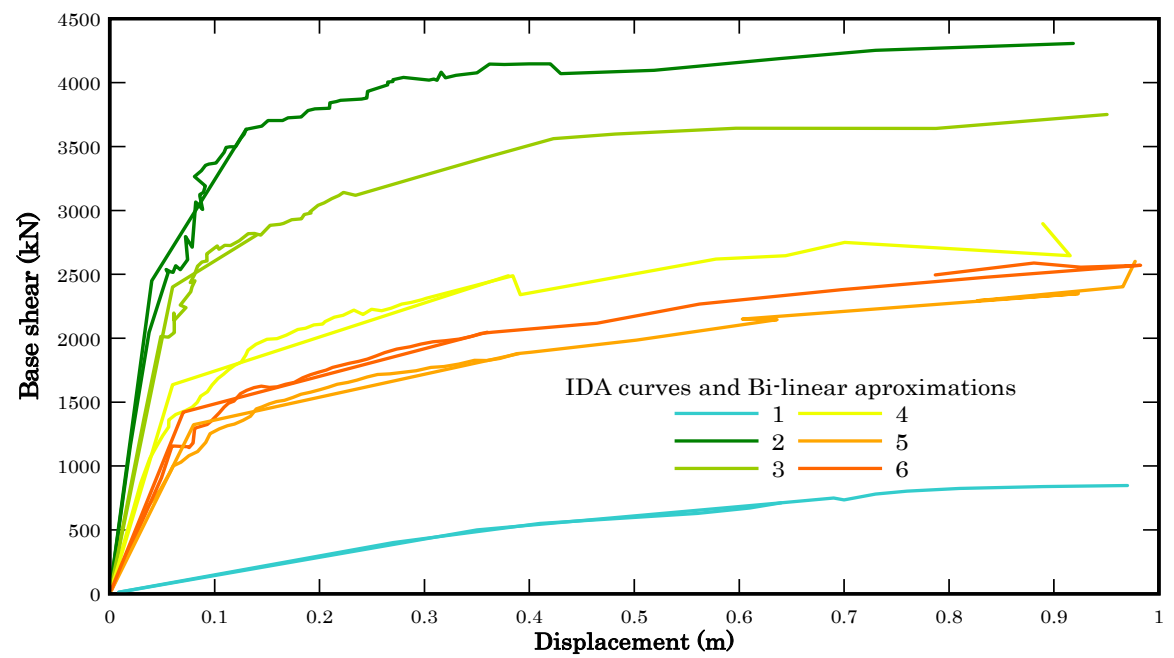

Fig. (11). IDA curves and bilinear approximations for 4 stories buildings.

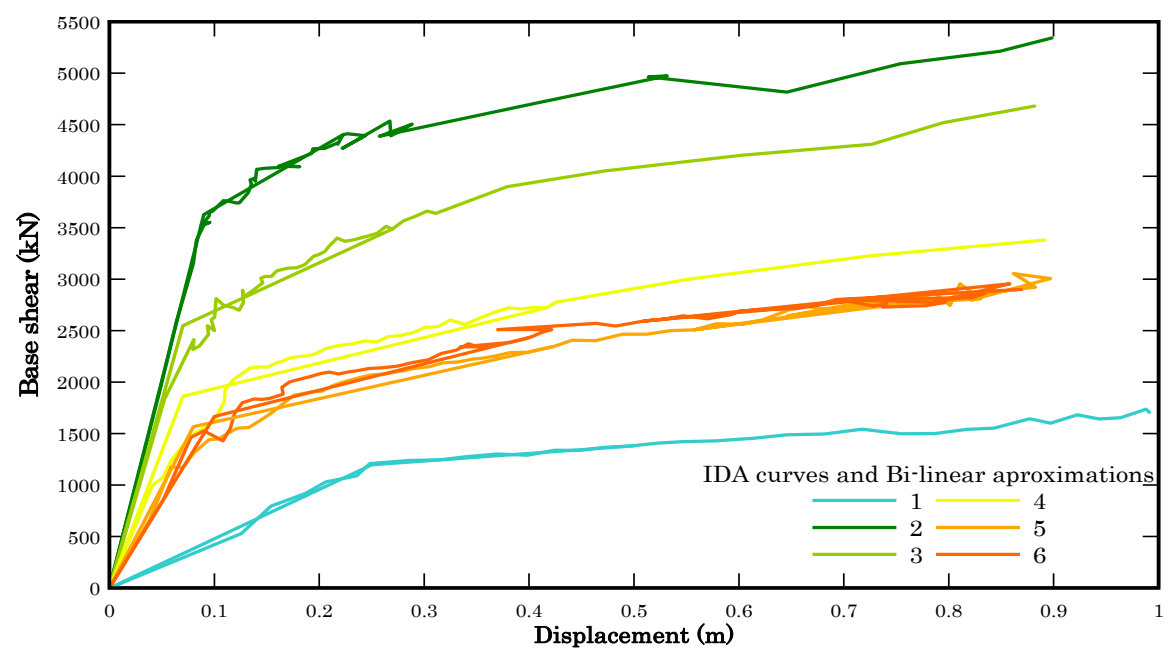

Fig. (12). IDA curves and bilinear approximations for 6 stories buildings. 


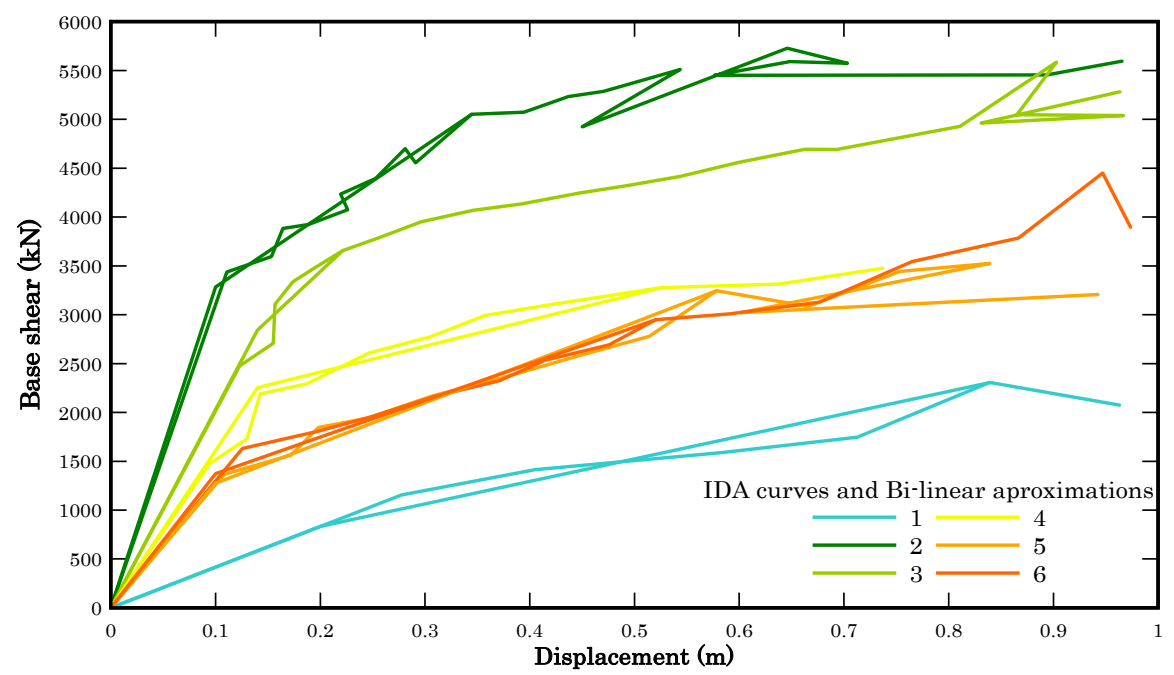

Fig. (13). IDA curves and bilinear approximations for 8 stories buildings.

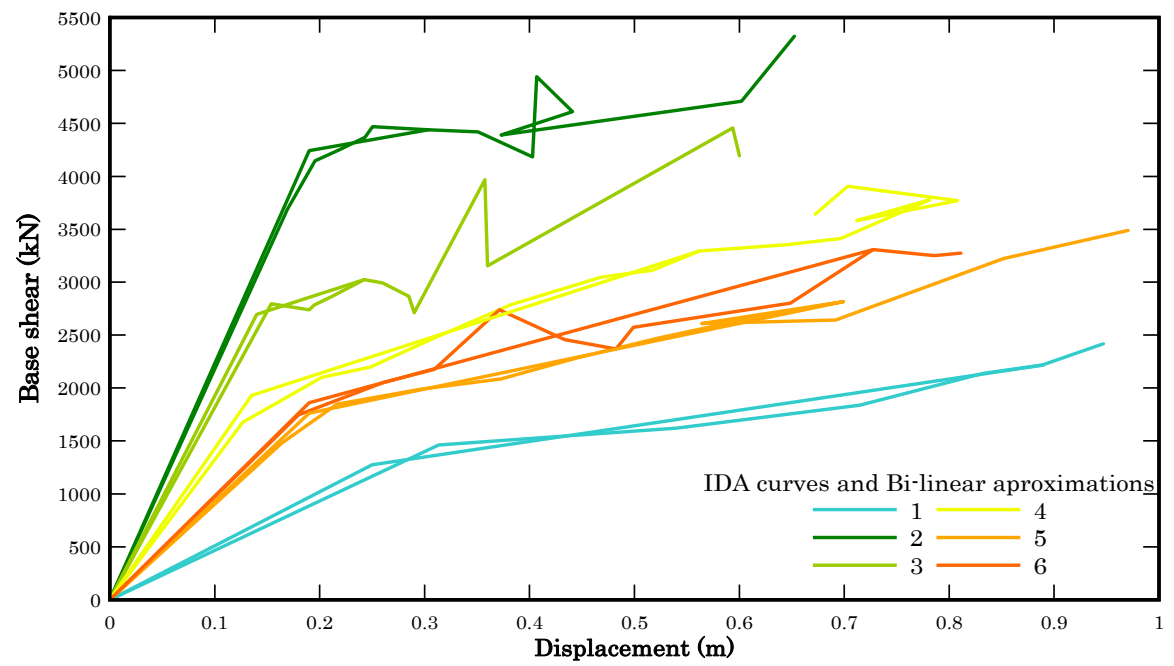

Fig. (14). IDA curves and bilinear approximations for the 10 stories buildings.

\subsection{Parameters of Seismic Response and Dissipation Energy}

\subsubsection{Parameters of Seismic Response: Overstrength ( $(\Omega d)$ and Ductility $(\mu)$}

According to the results, the concentrically braced frame in "X" (configurations 2) has the greatest overstrength factor; however the eccentric configurations achieved a significant increase of these values compared to building without braces (configuration 1). On the other hand the greatest ductility values correspond to the cases of eccentrically located braces (configurations 4, 5 and 6). Fig. (15), shown the overstrength hand ductility factors obtained by non-linear static analyses and incremental dynamic analysis specifically for 4 and 6 stories buildings.
4.4.2. Dissipation Energy Parameters: Elastic Deformation Energy (ESO), Energy Dissipated by Hysteretic Damping (ED) and Equivalent Damping ( $(\xi e q)$

The result of energy of elastic deformation (ESO) and energy dissipated by hysteretic damping (ED) that corresponds to non-linear static analysis shown a significant increase in the cases of EBF in inverted "V" with horizontal link (configuration 4), EBF in inverted " $\mathrm{Y}$ " (configuration 5), and EBF "X" with vertical link (configuration 6). As for the values of equivalent damping ( $\xi$ eq), eccentric configurations represent the cases with the highest values, while the lowest damping is obtained in cases of MRF and $\mathrm{CBF}$ in X. (configuration 1 and 2). Fig. (16).

Graph bars in Figs. (16 and 17) representing each of the six configurations studied. 


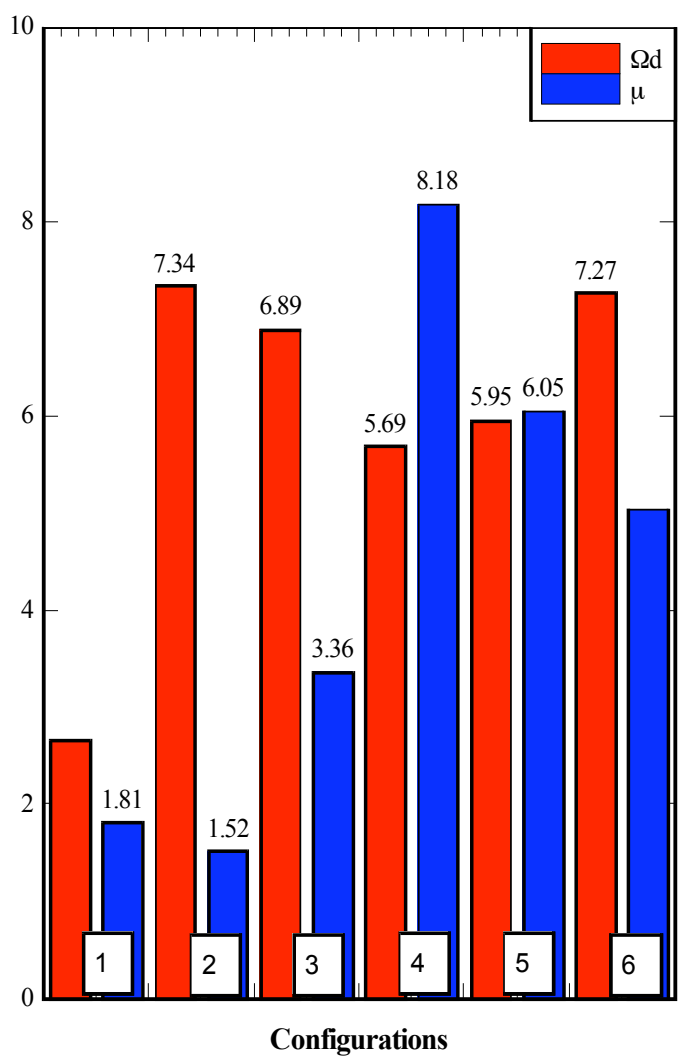

(a)

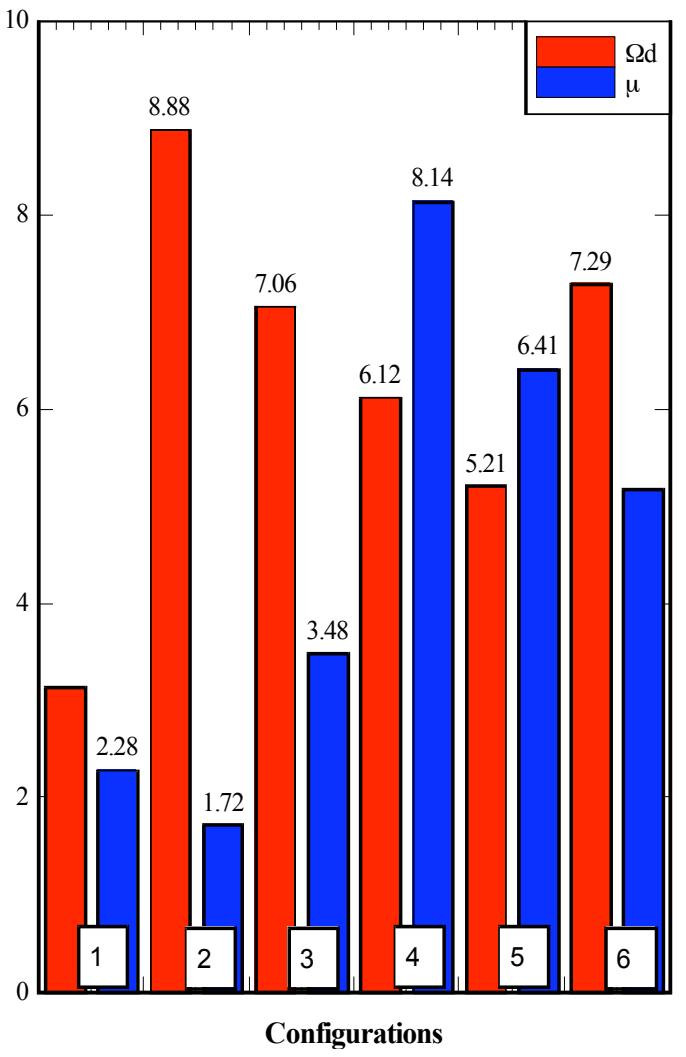

(c)

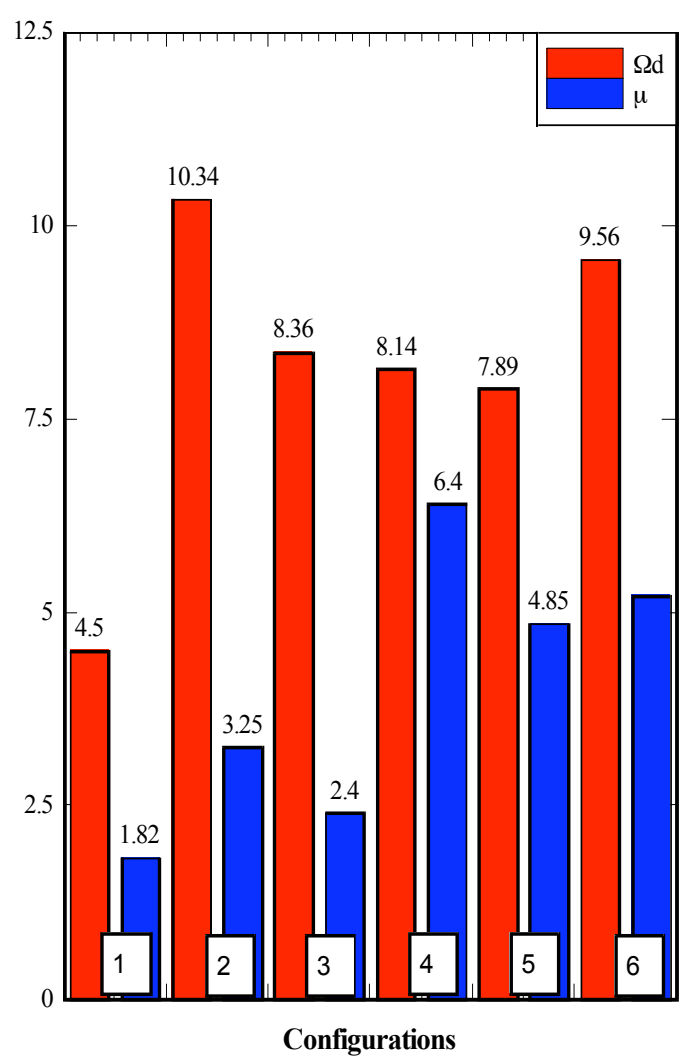

(b)

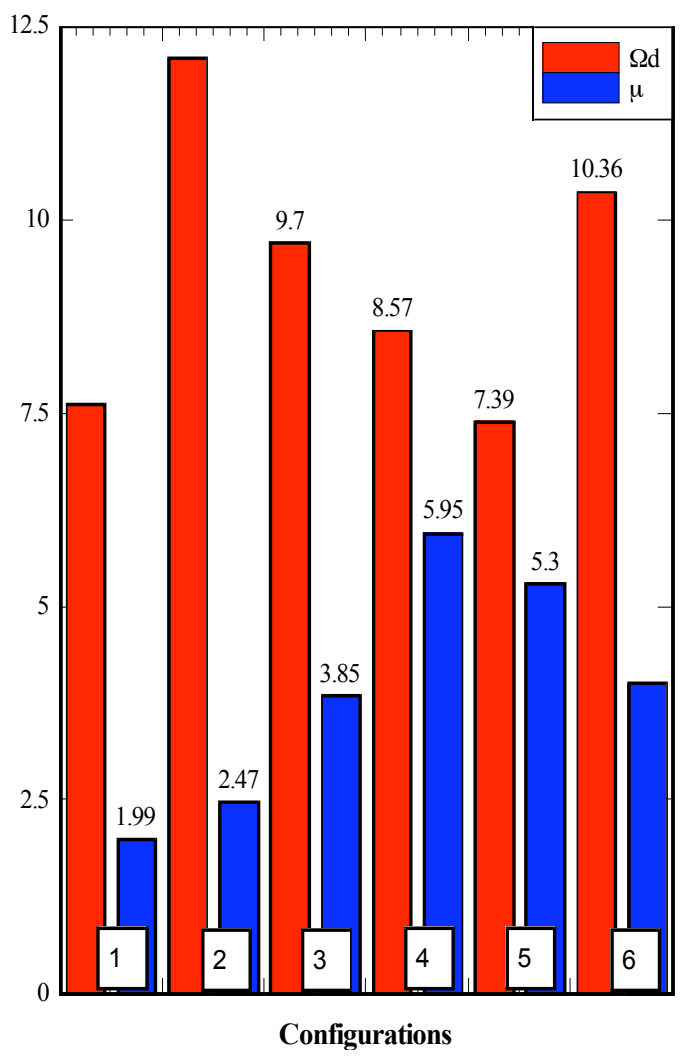

(d)

Fig. (15). Overstrength $(\Omega d)$ and ductility $(\mu)$ factors. Non-linear static analyses 4 stories (a), 6 stories (b); Incremental dynamic analyses 4 stories (c), 6 stories (d). 

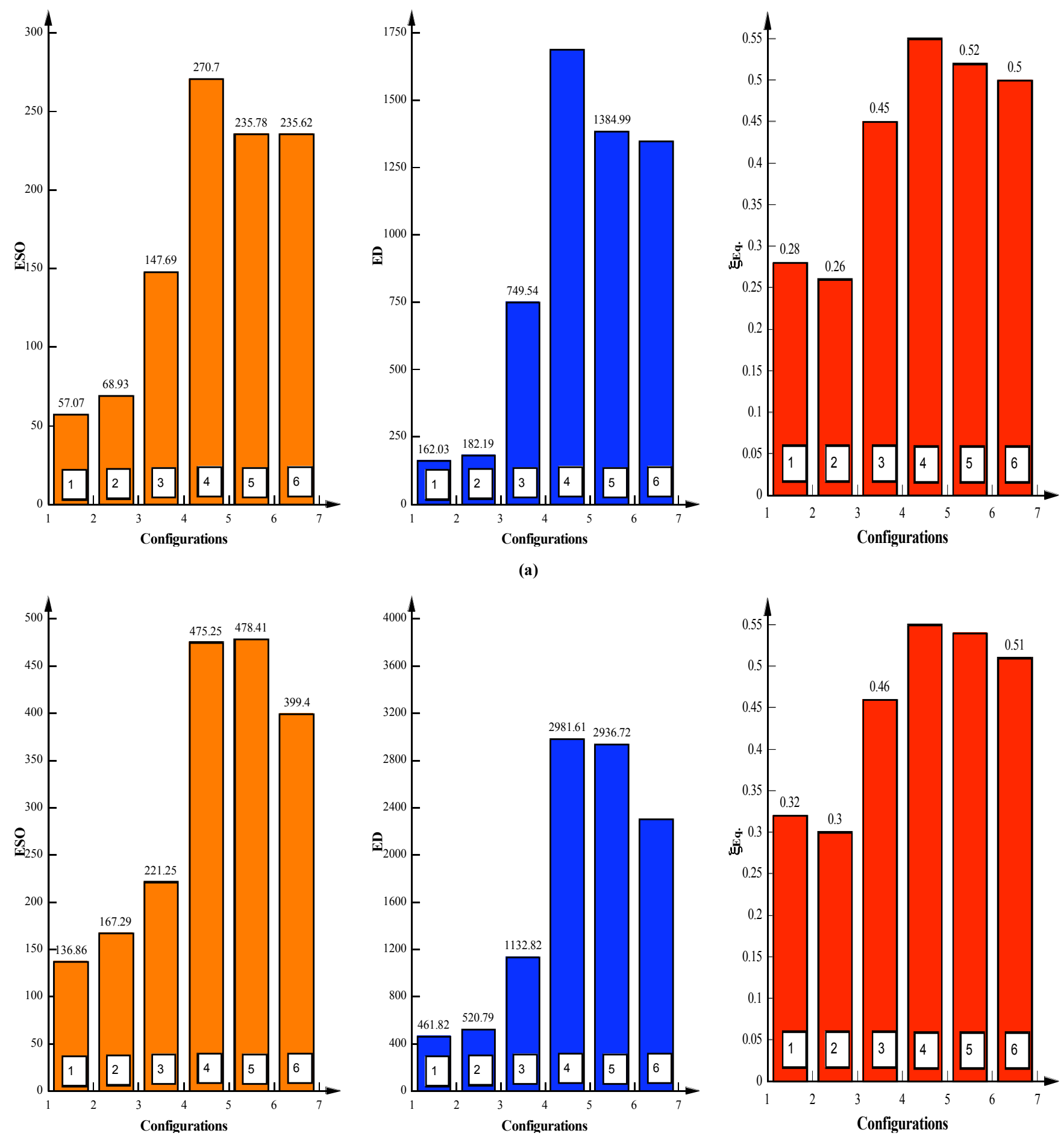

(b)

Fig. (16). Elastic deformation energy, (ESO,), KN-m ; Energy dissipated by hysteretic damping (ED), KN-m, Equivalent damping ( $\xi$ eq \%), for 4 (a) and 6 (b) stories buildings, Non-linear static analyses.

The elastic deformation energy (ESO) and dissipated energy by hysteretic damping (ED) corresponding to IDA analysis (Fig. 17) showed, just like non-linear static analysis, a increase in the cases of EBF (configuration 4, 5, and 6). As for the values of equivalent damping ( $\xi$ eq $\%$ ), eccentric configurations represent the cases with the highest values, while the lowest damping are obtained of MRF and CBF in X. (configuration 1 and 2).

\section{CONCLUSION}

In this paper, a comparative study of the behavior of steel structures of 4, 6, 8 and 10 stories, designed according Venezuelan code and upgraded with configurations of concentric braces (CBF on "X" and inverted "V") and eccentric braces (EBF in inverted "V "with link horizontal, inverted" $\mathrm{Y}$ "and" $X$ "with vertical link) has been presented. The structures were 

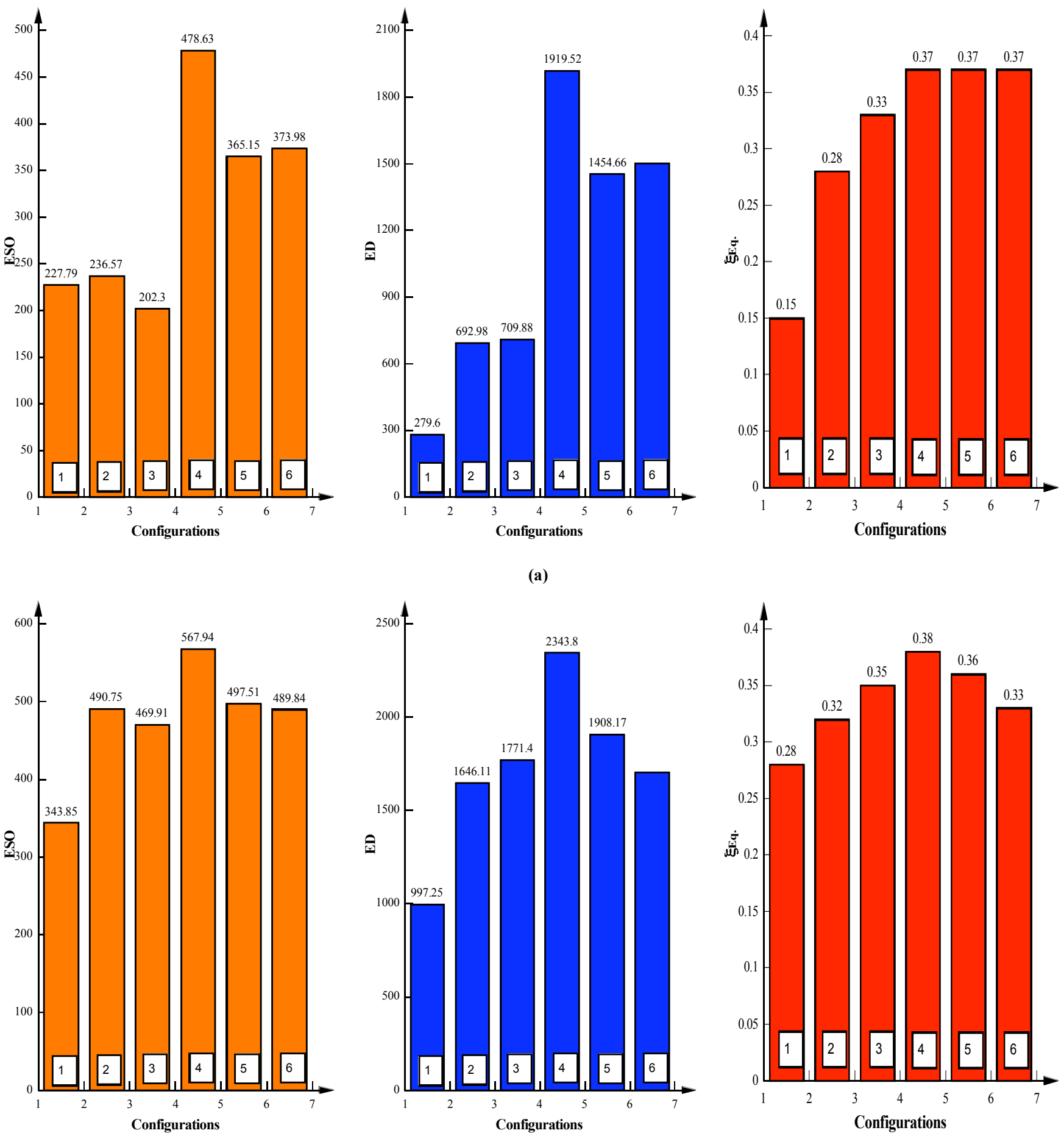

(b)

Fig. (17). Elastic deformation energy, (ESO,), KN-m; Energy dissipated by hysteretic damping (ED), KN-m, equivalent damping ( $\xi$ eq \%), for 4 (a) and 6 (b) stories buildings. Incremental dynamic analyses,

analyzed using non-linear static analysis (pushover analysis) and incremental dynamic analysis (IDA).

According to the results obtained in this research, the use of eccentric braces is an efficient way to resist seismic forces; it is possible to achieve significant reductions of the interstorey drifts when compared with MRF cases, which translates into low structural damage during the occurrence of earthquakes. EBF is the more ductile typology compared with the cases of CBF, and therefore greater energy dissipation capacity is achieved. The right choice of EBF configurations should be carefully studied, to avoid inadequate seismic behavior.

It is recommended to extend the present research to the analysis of steel structures with irregularities in plan and elevation, explore more configurations; as well as further laboratory testing for calibrate the results obtained. Finally, a 
detailed connections design $\mathrm{EBF}$ is recommended, following the seismic provisions of AISC-10 [22], to ensure appropriate behavior.

It is a moment to apply these technologies and improve the knowledge and the practice into the design and construction of eccentrically braced buildings in developing countries.

\section{CONFLICT OF INTEREST}

The authors confirm that this article content has no conflict of interest.

\section{ACKNOWLEDGEMENTS}

Declared none.

\section{REFERENCES}

[1] J.J. Egozcue, A.H. Barbat, J.A Canas, J. Miqueland, and E. Banda, "A method to estimate occurrence probabilities in low seismic activity regions", Earthquake Engineering and Structural Dynamics, vol. 20, no. 1, pp. 43-60, 1991.

[2] E. Márquez, W. Lobo, and J.C. Vielma, "Evaluación de la capacidad de disipación de energía de edificios de acero con diagonales excéntricas”, Sísmica Magazine, vol. 2, no. 7, p. 16, 2013.

[3] W. Lobo, E. Márquez, and J.C. Vielma, "Assessment of the energy dissipation capacity of steel buildings with eccentric braces", In: $15^{\text {th }}$ World Conference on Earthquake Engineering, Lisbon, Portugal, 2012.

[4] R. Herrera, J.C. Vielma, L.G. Pujades, and A.H. Barbat, "Estado del conocimiento sobre metodologías de evaluación de vulnerabilidad sísmica de edificios", Revista Ingeniería y Sociedad, vol. 8, no. 1 , pp. 7-28, 2012

[5] R. Ugel, J.C. Vielma, L. Romero, and S. Pérez, Respuesta Sísmica de Edificaciones Aporticadas de Acero de Mediana Altura Con Diagonales Tipo V Invertida Proyectados Conforme a Las Normas Venezolanas. Gaceta Técnica de Ingeniería Civil, 2012.

[6] J.C. Vielma, J. Pieruzzini, and A. Yústiz, "Evaluación del proyecto sismorresistente de pórticos de acero con diagonales concéntricas tipo cruz de San Andrés", Revista Internacional de Ingeniería de Estructuras, vol. 17, no. 1, pp. 1-21, 2012.

[7] J.C. Vielma, A.H. Barbat, and S. Oller, Proyecto Sismorresistente de Estructuras Porticadas. Monografía CIMNE IS, Barcelona, España, 2011.
[8] S. Ollerand, and A.H. Barbat, "Moment-curvature damage model for bridges subjected to seismic loads", Computer Methods in Applied Mechanics and Engineering, vol. 195, pp. 4490-4511, 2006.

[9] COVENIN-MINDUR 1618:1998, Estructuras de Acero para Edificaciones. Método de los estados Límites. Ministerio de desarrollo Urbano Fondonorma, Caracas, Venezuela, 1998.

[10] COVENIN - MINDUR 1756- 2001, Norma de Edificaciones Sismorresistentes. Ministerio de desarrollo Urbano. Fondonorma, Funvisis, Caracas, Venezuela, 2001

[11] J.C. Vielma, PACED: Programa Para Generación de Acelerogramas Compatibles Con Espectros. UCLA, Barquisineto, Venezuela, 2009.

[12] R. Ugel, R. Herrera, A.L. Barbat, and J.C. Vielma, "Análisis dinámico no lineal de edificio educacional con estructura de acero", Revista Internacional de Ingeniería de Estructuras, vol. 18, no. 1, pp. 103-120, 2013.

[13] A.H. Barbat, and L.M. Bozzo, "Seismic analysis of base isolated buildings", Archives of Computational Methods in Engineering, vol. 4, no. 2, pp. 153-192, 1997.

[14] J.C. Vielma, A.H. Barbat, and S. Oller, Non-linear structural analysis. Application to evaluating the seismic safet, in Structural Analysis. Nova Science Publishers: New York, Estados Unidos de América, 2010.

[15] J. Faleiro, S. Oller, and A.H. Barbat, "Plastic-damage seismic model for reinforced concrete frames", Computers and Structures, vol. 86, no. 7-8, pp. 581-597, 2008.

[16] X. Martinez, S. Oller, F. Rastellini, and A.H. Barbat, "A numerical procedure simulating RC structures reinforced with FRP using the serial/parallel mixing theory", Computers \& Structures, vol. 86, no. 15-16, pp. 1604-1618, 2008.

[17] E. Kalkanand, and S. Kunnath, "Method of modal combination for pushover analysis of buildings", In: $13^{\text {th }}$ World Conference on Earthquake Engineering, Vancouver, Canada, 2004.

[18] A.S. Elnashaiand, and S. Disarno, Fundamental of Earthquake Engineering, Reino Unido: Wiley, 2008.

[19] R. Moreno, "Evaluación del Riesgo Sísmico en Edificios Mediante Análisis Estático no Lineal. Aplicación a Diversos Escenarios Sismicos en Barcelona", Ph.D, Thesis, Universidad Politécnica de Cataluña, Barcelona, 2006.

[20] P. Dasgupta, S.C. Goel, G. Parra-Montesinos, and K.C. Tsai, "Performance-based seismic design and behavior of a composite buckling restrained braced frame", In: $13^{\text {th }}$ World Conference on Earthquake Engineering, Vancouver, Canada, 2004.

[21] D. Vamvatsikos, A. Cornell. "The incremental dynamic analysis and its application to performance-base earthquake engineering", In: $12^{\text {th }}$ European Conference on Earthquake Engineering, Elsevier Science Ltd, 2002.

[22] AISC Committee on Specifications, Seismic Provisions for Structural Steel Buildings. Chicago, Illinois, United Stated of America, 2012.

\section{Received: October 11, 2014 \\ (C) Marquez et al.; Licensee Bentham Open.}

Revised: November 24, 2014

Accepted: December 09, 2014

This is an open access article licensed under the terms of the Creative Commons Attribution Non-Commercial License (http://creativecommons.org/licenses/ by-nc/3.0/) which permits unrestricted, non-commercial use, distribution and reproduction in any medium, provided the work is properly cited. 